\title{
Un nuevo orden en la locura: estructuras disipativas en Desde los blancos manicomios, de Margarita Mateo Palmer
}

\section{A new order in madness: dissipative structures in Desde los blancos manicomios, by Margarita Mateo Palmer}

Lilianne Lugo Herrera Universidad de Miami, Estados Unidos

Resumen: El presente trabajo propone analizar la novela Desde los blancos manicomios, de la autora cubana Margarita Mateo Palmer, a partir de algunos conceptos del mundo de la ciencia, tales como las estructuras disipativas de Ilya Prigogine, la Ley de la Entropía, y los fractales de Benoit Mandelbrot. Dicho análisis permitirá mostrar cómo el diseño de la protagonista y su característica principal, la locura, así como la estructura fragmentada de la novela, las diferentes voces narrativas y el juego intertextual, permiten una lectura crítica y feminista de la literatura cubana y caribeña. La locura de la protagonista, además, se puede ver como la expresión de un desorden social y un mundo fracturado, que en este caso coincide con la realidad cubana de las décadas de los 90 y los 2000, ańos de profunda crisis económica tras la caída de la Unión Soviética y el campo socialista, y como una reacción de búsqueda de agencia intelectual femenina frente a una sociedad machista. 
Palabras clave: literatura cubana, literatura caribeña, locura, estructuras disipativas, agencia femenina.

Abstract: This essay analyzes the novel Desde los blancos manicomios, by Cuban author Margarita Mateo Palmer, using some scientific concepts, such as Ilya Prigogine's dissipative structures, entropy, and Benoit Mandelbrot's fractals. This analysis will show how the protagonist's main characteristic, its madness, as well as the fragmented structure of the novel, the different narrative voices and the intertextual play, allow a critical and feminist reading of Cuban and Caribbean literature. In addition to that, the protagonist's madness can be interpreted as an expression of a social disorder and a fractured world. That fractured world coincides in the novel with the Cuban reality of the 90s and the 2000s, years of a profound economic crisis after the fall of the Soviet Union and the socialist bloc. Finally, the essay will argue that the novel can be read as a reaction of the protagonist to search its feminine intellectual agency, in order to confront a normalizing and chauvinistic society.

Keywords: Cuban Literature, Caribbean Literature, Madness, Dissipative Structures, Feminine Agency.

Recibido: 22 de febrero de 2018 Aprobado: 5 de mayo de 2018

no es el amor ni el arte ni el desvelo de la gloria: es que a veces -tantas vecessiento el terror de la presencia humana.

"Explicaciones del equilibrista", Raúl Hernández Novás

Desde los blancos manicomios, publicada en Cuba en 2008, es Palmer. La misma recibió ese año el Premio Alejo Carpentier de la 
UNEAC, uno de los más prestigiosos premios de narrativa otorgados en Cuba. Mateo, sin embargo, era ya una autora reconocida en el país por su amplia obra ensayística. ${ }^{1}$

En Desde los blancos manicomios, Margarita Mateo Palmer establece una estructura narrativa de alta complejidad intertextual. En ella, la locura del personaje principal, Gelsomina, es la excusa que permite mezclar el discurso de lo cotidiano -los conflictos de cada personaje, la realidad cubana del momento y los recuerdos de los últimos años en la Isla- con sus opiniones y conexiones intertextuales acerca de la literatura caribeña. A partir de algunos conceptos del mundo de la ciencia, tales como las estructuras disipativas de Ilya Prigogine, el principio segundo de la Ley de la Termodinámica, o Ley de la Entropía, así como los fractales de Benoit Mandelbrot, propongo una lectura de Desde los blancos manicomios que privilegia cómo el diseño de la protagonista, así como la estructura de la novela, permiten una lectura crítica de la sociedad cubana durante el período especial y durante los ańos posteriores a éste, al mismo tiempo que propone una visión feminista de la literatura cubana y caribeña.

Como el equilibrista que se lanza a la cuerda floja y reniega de la fama y el amor en el poema de Novás que uso como exergo, una profesora de literatura y escritora entra a un manicomio, pasa días enteros debajo de la cama, acompañada sólo de los libros, asustada de las enfermeras y la noche, hasta que logra restablecerse y, aparentemente, volver a la realidad. Pero, por principio físico, de acuerdo a la segunda ley de la Termodinámica, ${ }^{2}$ la entropía ge-

${ }^{1}$ Mateo Palmer recibió en el 2016 el Premio Nacional de Literatura en Cuba, la distinción más importante de las letras cubanas, por el conjunto de su obra. ${ }^{2}$ Enunciada en la década de los 1850 por Rudolf Clausius, la entropía se refiere a la cantidad de energía no reutilizable en un sistema tras cierta transformación, y por tanto alude también al grado de desorden en ese proceso. Si un proceso químico desprende cierta energía no utilizable, entonces resulta irreversible (ya que la energía disipada no puede volver a su estado inicial). En ese sentido, por 
nerada por un sistema hace imposible la irreversibilidad. La que entró al manicomio, como si entrase al río de Heráclito, nunca será la misma que sale: Gelsomina (así se llama la escritora alucinada que deambula por una Habana fractal, donde convergen todas las islas del Caribe, cual Aleph tropical). En su libro El nacimiento del tiempo, el Premio Nobel de Química Ilya Prigogine explica varios de los conceptos creados por él alrededor de los estados de noequilibrio en el mundo de la química. Prigogine comenta cómo previamente se creía que el estado de no-equilibrio era equivalente a un estado de desorden, y cómo los nuevos experimentos han desmentido dicha suposición. El científico afirma: "cuando se afronta el dominio del no-equilibrio, se establecen nuevas interacciones de largo alcance: el universo del no-equilibrio es un universo coherente" $(1993,49)$. Estas nuevas estructuras que se producen en los estados de no-equilibrio serán las estructuras disipativas. En el noequilibrio la materia fluctúa, no se mantiene de forma homogénea, y esto da paso a nuevas posibilidades. La presencia de estas estructuras disipativas comprueba que en el mundo de las partículas la carencia de orden no implica necesariamente caos o desorden, sino nuevas formas de organización. Este tipo de planteamiento permite evadir los estados binarios, la concepción de que el mundo funciona solamente por oposiciones: caos/orden, cordura/locura. Del mismo modo, la locura, asociada históricamente a un mundo de caos mental, a un desorden de los sentidos que sitúa al loco fuera de la norma -recuérdese el tropo medieval de la piedra de la locura, y los tratamientos médicos que en el siglo XX la situaron como una enfermedad, más que como un fenómeno social-. Hoy se conoce que la locura no es más que un nombre genérico para trastornos sumamente diversos desde el campo de la psicología, psiquiatría y neurología.

tanto, la entropía ha sido utilizada para aludir a todo proceso irreversible que ocurre en la naturaleza y en la sociedad. 
En este ensayo propongo entender la locura de Gelsomina como un estado de no-equilibrio, en el cual aparecen estructuras disipativas -elementos literarios que serán explicados más adelante- que generan un nuevo orden en el discurso del personaje y obviamente de la novela. Dichas estructuras permiten, en definitiva, la ruptura de las normas socio sexuales de la sociedad cubana, y la entrada a un discurso crítico sobre la realidad cubana y la literatura caribeña. Según Prigogine, la materia en el estado de equilibrio es ciega, sólo puede ver e interactuar con las partículas que se encuentran a su alrededor. Sin embargo, lejos del equilibrio la materia puede hacer conexiones a más larga distancia: "en una situación alejada del equilibrio se producen las correlaciones de largo alcance que permiten la construcción de los estados coherentes" (1993, 84-85). Para Gelsomina, la distancia de lo real, entonces, de la cotidianidad de la madre, el hijo, las obligaciones laborales y las necesidades económicas, constituyen lo que pudiéramos llamar un estado de equilibrio, pero que, para ella, representa un período ciego en materia de creatividad. Al lograr percibir la realidad de otra forma, alejándose de la rutina cotidiana, Gelsomina puede percibir la interconectividad caribeña del espacio insular y de sus motivos literarios. En los libros que la rodean, a su vez, Gelsomina se ve a sí misma, como dos espejos enfrentados, reproducidos fractalmente, hasta el infinito.

En lugar de presentar de manera negativa la experiencia de aislamiento y la ruptura emocional del personaje, Mateo Palmer propone una revisitación de los tropos asociados a la locura, situando su desequilibrio como el momento que permite estas nuevas conexiones. Dentro de las estructuras disipativas -que a mi juicio funcionan como detonadores de nuevas experiencias para la protagonista, y como catalistas dentro de la narración- se encuentran los elementos metaliterarios, la intertextualidad y autorreferencialidad del texto, la discusión de los tropos más frecuentes de la literatura 
caribeña y el embodiment (encarnación o puesta en cuerpo) ${ }^{3}$ de dichos elementos en el cuerpo de la protagonista.

Aunque los procesos de referencialidad y metaliterariedad de la novela son frecuentes a lo largo del texto, comenzaré por analizar los nombres de la protagonista como una primera evidencia. Gelsomina es el nombre del personaje de La Strada de Fellini, aquel que interpretara magistralmente Giulietta Masina. Esta Gelsomina, en cambio, pasa por un proceso de transfiguraciones, pues los ojos espectatoriales del poeta Raúl Hernández Novás le dedicaron un libro de sonetos. Gelsomina, entonces, no es sino el álter ego de la locura para el nombre de la protagonista. Según su madre, el nombre real sería María Mercedes Pilar de la Concepción. El nombre dado por la madre evoca otra serie de cuestiones referenciales al acto de nombrar: Dulce María Loynaz, una de las más prestigiosas autoras cubanas, en realidad se llamaba María Mercedes; el sujeto poético a quien se dirige una de las obras más mencionadas en la novela, el poema "The Schooner Flight", de Derek Walcott, se llama María Concepción, y Pilar es el nombre del personaje del poema de José Martí "Los zapaticos de rosa". El nombre real del personaje literario aparece entonces como una encarnación de otros personajes o autores importantes de la literatura caribeña. Especialmente en el caso de Dulce María Loynaz, hay una fuerte relación entre el personaje de su novela Jardín, Bárbara, quien se rehúsa a salir de su mansión, y el sentido de reclusión de Gelsomina. La propia Dulce María vivió los últimos días de su vida olvidada en su casa del Vedado, apartada de la vida social, hasta que la noticia del Premio Cervantes la rescató del olvido oficial de las

${ }^{3}$ Estos dos términos serán usados según el contexto, pero siempre en referencia al acto de to embody en inglés: la apropiación de algo y su puesta en cuerpo. El término encarnación aparece como la traducción más cercana, pero este vocablo contiene un cierto significado religioso que no es pertinente para este trabajo. Al usarlo, se pondrá en cursivas, para destacar su conflictividad. 
instituciones culturales cubanas. La reclusión fue, para estas mujeres y personajes, la única opción que tuvieron, pero también lo que les permitió alcanzar autonomía intelectual, y de mostrar una diferencia con respecto a los imperativos sociales del momento. Es justamente esto lo que la madre le critica a Gelsomina, la vida intelectual que a la madre le resulta enfermiza, justamente porque implica negar el rol doméstico que ésta asume como imperativo social. Gelsomina no puede resignarse a una vida normativa regida bajo los órdenes de lo femenino tradicional, del mismo modo que Dulce María Loynaz se recluyó en su mansión, negada a participar de los vítores entusiastas del pueblo revolucionario.

Desde los blancos manicomios se compone de cuarenta y un capítulos, organizados a modo de serie, donde a cada parte corresponde un narrador específico. Así, existen ocho capítulos titulados "La carrera interminable", donde el hijo de la protagonista cuenta su perspectiva sobre su madre, además de sus propios conflictos; en los ocho capítulos titulados "Habla la marquesa roja", es la madre quien, dirigiendo su diatriba a la doctora de Gelsomina, muestra su visión de la hija y el nieto; finalmente, en las ocho "Cartas a Gelsomina”, María Estela, la hermana que vive en Miami, se queja de su vida en otro país, a la vez que describe la abundancia y calidad de los productos que puede comprar, comparándolos con la escasez material permanente en Cuba. La otra serie se titula "Gelsomina en...", donde cada capítulo alude a un lugar diferente, "Gelsomina en la costa”, “...en el jardín de la ciudad”, etcétera. El narrador en estos capítulos es, en general, en tercera persona y narra lo que pasa por la mente de Gelsomina, los comentarios del personaje del suicida, lo que ocurre a Gelsomina en el hospital psiquiátrico e incluso algunos flashbacks al pasado de ésta antes de la crisis.

El capítulo 21, "Gelsomina y las brujas", justo a la mitad de la novela, es el único que no sigue las estructuras anteriores, pues, 
utiliza la conjunción copulativa y; recalco lo importante de la cópula, por razones que explicaré más adelante, pero que dan sentido global al texto. Este capítulo remite a un pasado anterior al manicomio, en el que la protagonista, mientras limpia la casa, y a partir de la relación entre la escoba de la bruja y su propia escoba, analiza algunas brujas literarias - como la Margarita de Mikhail Bulgakov y la Tituba de Maryse Condé- y sus significados. El acto del trabajo doméstico, y no "escuchando a Vivaldi desde una poltrona" (Mateo Palmer, 2010: 144), es lo que inspira al personaje su acto de reflexión acerca de la relación entre el sufrimiento y la locura:

¿Podría, efectivamente, establecerse una relación directa entre el sufrimiento y la vocación de bruja? ¿Podrían conducir el dolor y la angustia sostenidas, no ya a los altos manicomios, sino al inefable vuelo sobre la escoba? ¿Existiría una relación entre la mujer y la locura? ¿Entre lo femenino y el camino diabólico? ¿Ambos viajes como posibilidades de fuga del mundo cotidiano? (Mateo Palmer, 2010: 151).

Curiosamente, esta posibilidad de fuga, inherente a la bruja gracias a la escoba, conlleva una agencia negada a la mujer y su tradicional encierro doméstico. Gelsomina analiza una imagen de 1480 , encontrada en un diccionario, en la que se muestra una bruja copulando con Satán, donde ésta es la que tiene la posición activa: "Él, con toda su fealdad, más bien parece violado, forzado, y observa con cierto estupor cómo su cuerpo es absorbido en el hueco negro e insaciable del deseo femenino" (Mateo Palmer, 2010: 147). La bruja encarna un espacio de agencia social, de poder a través del sexo, que la protagonista de la novela asume para sí. Al final del capítulo, un misterioso personaje masculino entra a la escena, y la lleva a la cópula. Con el acto sexual se inicia también el movimiento limpiador de las escobas, autónomas, por toda la casa. Evidentemente Gelsomina es situada en la narrativa como 
una encarnación de la imagen sexual de la bruja. Al acto repetitivo y monótono del trabajo doméstico, se superpone el acto mágico del deseo femenino como actante de cambio.

Lo contrario de esta actitud aparece en el personaje de la madre, quien representa los atributos de la feminidad normativa y compulsiva: su placer está en servir al nieto, cuidar la casa y criticar las posturas "extravagantes" de la hija. Para hacer volver a su hija a lo que considera lo normal, no vacila en mutilar sus libros, regañarla, desacreditarla y, últimamente, intentar convencer a la psiquiatra de que la deje encerrada. La madre no sólo representa un modelo de feminidad retrógrada, sino que impide el desarrollo de su hija, por considerarlo desviado. Como asevera la antropóloga mexicana Marcela Lagarde: "El esquema de la racionalidad dominante exige de la mujer que no tenga poder, que si lo tiene, no lo exhiba, que no actúe sobre los otros, más que en las formas maternas o eróticas aceptadas, que no sea inteligente, ni autónoma, ni poderosa, y que no sea mala" (2003: 732). La madre de Gelsomina, por tanto, atribuye toda la locura de la hija no a la situación económica del país, ni a la presión de la maternidad, o a su propia actividad coercitiva, sino que lo atribuye a la lectura. Para la madre, el espacio de poder de Gelsomina es fuente de todo mal. La mujer inteligente, como la bruja, representa en la cultura tradicional y machista que aún impera en las sociedades caribeñas, un símbolo peligroso y que, por tanto, debe ser contenido, alejado, purificado.

En su análisis sobre la relación entre locura y feminidad, Lagarde se aproxima a las diferentes tipologías de locas que la sociedad construye. Para Lagarde, la locura en sí es un resultado del proceso de sufrimiento, de desgaste emocional y físico como producto del cuidado y servicio hacia "los otros", y la falta de cuidado y reconocimiento social de ellas mismas. En la maquinaria reproductiva, doméstica y erótica que produce en la sociedad patriarcal oprimidos cuerpos femeninos, la locura emerge como una consecuencia 
que es, además, castigada socialmente con el alejamiento, los tratamientos médicos y la devaluación social. Curiosamente, Lagarde señala dentro de las locas la tipología de las brujas como una forma especial de locura y descalificación social, pero destacable pues éstas poseen conocimientos y por tanto poder: "Por ser aliadas del mal y del pecado, las brujas son la mujer-pecado. Su pecado se funda en la desobediencia, en la sabiduría y el erotismo" (2003: 731). Es justamente este referente el que Mateo Palmer utiliza para el personaje de Gelsomina, en tanto encarna el cuerpo de la bruja, en el capítulo "Gelsomina y las brujas"; además, al ubicarlas dentro de la literatura como un tropo recurrente, a pesar de que repite la idea de castigo-reclusión, sí muestra una zona de agencia y poder para el cuerpo de la mujer-bruja.

La hospitalización de Gelsomina repite el esquema del alejamiento del cuerpo enfermo del resto de la sociedad, y en ese sentido funciona como una cárcel. Sin embargo, Mateo Palmer logra subvertir este símbolo de disciplinamiento social, pues ubica en la narrativa los tropos del aislamiento, el manicomio y la locura, pero para remarcarlos como espacios de poder de la protagonista. La novela comienza con la llegada de Gelsomina al manicomio: "Aquel lugar fue, sin duda, un sitio de poder para Gelsomina" (7). Contrariamente a la norma social, que elimina todo tipo de autonomía para los enfermos en los manicomios, para Gelsomina su estadía se convierte en un espacio de poder. En ese momento, y en una relación intertextual con El coloquio de los perros de Miguel de Cervantes y Saavedra, los perros en las puertas del manicomio discuten la entrada de Gelsomina. Ella misma les pregunta: “¿Entro o no entro?” (8), variante del famoso ser o no ser shakespeariano. Es decir, la entrada al manicomio está sujeta a la consulta literaria, poetizada en el referente, y no se reduce a la descripción de la violencia de la internación, ya sea forzada o no. Así mismo, el resto de su estadía en el manicomio estará signada por los diálogos 
intertextuales como expresión del poder intelectual, así como con las fuerzas de los dioses del panteón yoruba, en una versión de la comunicación que Gelsomina, como bruja, emprende para su propia curación. Estos dos elementos: la relación intertextual puesta en cuerpo, y la comunicación con las fuerzas religiosas afrocubanas, pueden constituir estructuras disipativas, pues en el caos aparente de los sentidos del personaje, otro tipo de conexiones empiezan a fluir y a llevarla, por caminos diferentes, a un nuevo estado de equilibrio.

El viaje de un estado de aparente orden al caótico desorden de la locura empieza una mańana, cuando Gelsomina "confundió su cama con una balsa y la ciudad con un jardín”, "El amplísimo vergel de la ciudad parecía extenderse hacia el infinito, continuar incluso más allá del muro que ahora la separaba del mar...” (9, 16). A partir de ahí, encontramos una dislocación de los espacios: caminar por La Habana es caminar por otras ciudades caribeńas: Fonds Rouge, el Cibao, los campos de Haití, todo confluye en un mismo lugar, un espacio tiempo habitado por Gelsomina. Del mismo modo, una vez internada, el personaje se rehúsa a salir de debajo de la cama, donde lee continuamente: su cama balsa la hace experimentar que viaja -como en el tropo medieval de la nave de los locos, a quienes se lanzaba al mar como forma de exclusión-. El viaje de Gelsomina, si bien no geográfico, resulta un viaje sensorial y de la memoria. Estas experiencias, que ocurren a veces también durante el sueño, la hacen percibir que los espacios forman un continuum que desdice la realidad:

No existían los límites. No había fronteras. Se asomó a la terraza. Supo entonces que su casa era parte del gran jardín de la ciudad. La puerta de su hogar no marcaba el tránsito de un espacio íntimo, doméstico, privado, cerrado, a otro público, colectivo, abierto, agórico. Ambas zonas, antes bien delimitadas, formaban parte de un continuum sin oposiciones ni conflictos. . . descubrió que 
los espacios ajenos también podían superponerse a través del viaje de la memoria... (Mateo Palmer, 2010: 14-15).

Si los fractales, según Benoit Mandelbroit, se caracterizan por tres elementos fundamentales: su capacidad de autosemejanza, repetición y fragmentariedad; en el viaje de la memoria de Gelsomina podemos encontrar esta capacidad fractal, asociada a los modos de leer y experimentar sensorialmente la vida. Mientras la madre achaca a los libros la locura de Gelsomina, y la hermana a la pobreza material, Gelsomina intenta comprender sus propias operaciones mentales de otra manera:

Negada a aceptar la teoría del caos, Gelsomina se dispuso a encontrarles un sentido a tantas transformaciones, y decidió observar atentamente los acontecimientos que protagonizaban los objetos al cambiar de lugar. Una causalidad invisible que aún no había podido descubrir, pero que estaba en la base de toda esta disipación otorgándole un sentido.

Gelsomina observó atentamente a su alrededor, y pensó que quizás lo que había considerado un desorden no fuese más que un nuevo orden (80-1).

Consciente de que el caos no es tal, sino tal vez la presencia de un orden incomprensible, el viaje de la memoria de Gelsomina, ocurrido por demás gracias al tiempo de inactividad doméstica que le provee el manicomio, permite una relación fractal con los objetos de la memoria. Así, se repiten espacios semejantes, conectados uno al otro de maneras fragmentadas. Por ejemplo, el tema de la insularidad es uno de los más evidentes, y aparece de maneras diversas: como evocación de los espacios geográficos del Caribe, en el análisis de la obra de Virgilio Piñera, Derek Walcott y Aimé Cesaire, entre otros, y por último en el propio cuerpo de Gelsomina. El piso bajo la cama, o la cama balsa, son espacios de aislamiento 
-insularidad- para Gelsomina, pero también espacios repetidos e interconectados gracias a la literatura y la memoria.

El Caribe, ya presentado en términos fractales por Antonio Benítez Rojo en su obra La isla que se repite: el Caribe y la perspectiva posmoderna, ha sido desde entonces analizado desde el ensayo académico de modos mucho más interconectados. Según Benítez "el Caribe no es un archipiélago común, sino un meta-archipiélago... y como tal tiene la virtud de carecer de límites y de centro" (1989: V). La isla que se repite, por tanto, resulta un motivo fractal, un espacio geográfico autosemejante y repetido, aunque fragmentario, incompleto. Margarita Mateo Palmer propone una jugada audaz, utilizar la novela como medio de discurso ensayístico, autorreferencial a su propia obra en este género.

Si el ensayo como género presupone que existe un metalenguaje que puede descifrar un texto literario u objeto cultural determinado, aplicando un número de variables o presupuestos teóricos, lo hace apelando a un discurso científico que borra, al menos en el ensayo académico tradicional, la posición del escritor y su particular mirada o experiencia personal sobre los fenómenos analizados. En el campo científico, en cambio, desde hace años se observa y valora, cada vez más, el papel de las mediciones y la influencia de un espectador ante la materia. ${ }^{4}$ Mientras el lenguaje académico pretende que el autor se borre como observador, presentando argumentos para que éstos hablen por sí mismos, la ciencia intenta encontrar cómo el observador es también participante y co-creador de determinados fenómenos. Para hablar de literatura, entonces, desde la literatura misma, Mateo Palmer crea un personaje/

${ }^{4}$ En el campo de las partículas subatómicas, por ejemplo, el papel del espectador es mucho más significativo, pues según algunos experimentos, la forma en la que la materia se comporta de manera diferente en presencia de un observador. Esto se conoce como efecto del observador. El trabajo de John Wheeler y Richard Feynman fue pionero en este campo (para más información véase a Haltern). 
observador/autor que transmita, en primer lugar, su posición ante el objeto de estudio.

La novela nos presenta una lectura mediada, incierta como el destino de Gelsomina, pero que gracias a esa misma condición resulta sumamente atractiva, pues le permite teorizar desde su propio cuerpo, utilizando lo sensorial, y la ficción misma, como método de crítica literaria. Así, el discurso ensayístico sobre la insularidad se reparte en varios capítulos, que a la vez ahondan en la obra de uno o varios autores caribeños. Por ejemplo, en "La noche insular" es Lezama quien aparece (pero asociado a una visita de Gelsomina al cementerio de Colón, a la tumba del poeta) encarnando -tanto por su vestimenta como por el lugar- a Oyá, la diosa del cementerio en la religión yoruba. En "La isla maldita" será Virgilio Piñera quien permita la meditación sobre la condición insular, gracias a "La isla en peso", uno de sus más famosos poemas, lo que hace aseverar a Gelsomina que el isleño es un "Sísifo antillano, cargando sobre sí el enorme peso de una isla que lejos de permitirle descansar sobre ella se convierte en terrible carga, el insular está condenado a un desplazamiento ilusorio que no es progreso sino redundante estatismo" (Mateo Palmer, 2010: 92). En la reflexión, es el propio personaje quien se encuentra sujeto al encierro (el manicomio), a la atadura física, de ahí el doble nivel entre el ensayo y la narrativa; a medida que avanza la primera, se desarrolla la segunda. En "Las islas del dolor", mientras tanto, Mateo utiliza a Julia de Burgos, la poeta puertorriqueña, y comenta la necesidad de ésta de crear un doble poético para rechazar los convencionalismos de la feminidad del momento (nótese la relación entre la estrategia de Julia de Burgos y el doble de la protagonista). Mateo narra la muerte de Julia, y su propio recorrido por La Habana, buscando el lugar donde ésta viviera con su amante. El mar que viera Julia es el mismo que ve Gelsomina. El fin de Julia, muerta en las calles de New York, sin que nadie la identificase hasta semanas después, confirma la 
relación entre locura y feminidad fuera de la norma que Mateo desarrolla como un tipo de agencia particular ante las agresiones del ambiente.

Estas ideas sobre la insularidad (explicadas desde la novela con la lectura de La revista del Vigía, en un ejemplar que Gelsomina posee en el hospital) aparecen, de otra manera, expresadas en el capítulo "La insularidad" en El Caribe en su discurso literario, libro de Mateo coescrito con Luis Álvarez Álvarez. Capote Cruz, por ejemplo, encontró la existencia de un artículo de Mateo Palmer titulado "Mapa insular de la poesía caribeña” en La Revista del Vigía, publicación cubana real producida en la ciudad de Matanzas (2013: 546). Ambos ensayos confirman la existencia de un discurso crítico similar al que establece la novela, a la vez que son referenciados por ésta. Se genera un entrecruzamiento creativo de varios géneros, gracias al desenfado autoral en materia autoreferencial. Asimismo, el personaje de Gelsomina, como ya han comentado otros autores, ${ }^{5}$ contiene numerosos elementos autoficcionales con su autora. El discurso de la novela pasa al plano de lo real y viceversa.

Otro momento importante dentro del discurso sobre la insularidad que plantea la novela ocurre como un flashback del personaje, en una ocasión anterior al momento de la locura. El capítulo se titula "Gelsomina en la Universidad Blaise Pascal", y narra cómo ésta, a la salida de la biblioteca de la universidad francesa donde se encuentra haciendo una investigación, tiene una serie de encuentros misteriosos y conexiones fantásticas. Así, y mientras camina por la ciudad francesa Clermont-Ferrand, Gelsomina transpone realidades y mitos caribeños al espacio europeo. Tras haberse encontrado con Maryse Condé en un pasillo de la universidad, y después de reflexionar sobre la importancia de las supersticiones en el contexto del Caribe, Gelsomina sale a la ciudad y entra a

${ }^{5}$ Véase a Capote Cruz, Pérez Hernández, Díaz Mantilla y Schutte. 
una iglesia que es, a un tiempo, el santuario de la Virgen de Regla en La Habana, y la iglesia de Notre Dame du Port. La basílica europea y el santuario cubano adonde confluyen tanto católicos como yorubas se fusionan en un espacio tiempo: el tiempo de la fe. El capítulo termina con la referencia al poema "Isla", de Virgilio Piñera, pero si en este autor la posibilidad de volverse isla quedaba relegada al futuro, en el texto de Mateo Gelsomina se vuelve isla en el presente. La relación entre insularidad y cuerpo femenino se cierra en ella. El análisis de ambos textos permite ver cómo la autora dialoga con el referente del poema, dejando claro que lo evoca, pero al mismo tiempo su conversión es diferente.

Se me ha anunciado que mañana, a las siete y seis minutos de la tarde, me convertiré en una isla, isla como suelen ser las islas.

Mis piernas se irán haciendo tierra y mar... (Piñera)

Volcada sobre sí misma a las seis y siete minutos de la tarde, cuando el crepúsculo difuso hace estallar las ciudades antillanas como una fiesta innombrable de colores y sombras, regresó Gelsomina, ya isla, a la Universidad Blaise Pascal, arrullada por las olas que batían sus costas, las piernas confundidas con la tierra, sus brazos germinando en frondosos árboles frutales, una hermosa ceiba naciendo en sus cabellos... (Mateo Palmer, 2010: 251).

El cuerpo de Gelsomina se presenta en una metáfora de fusión con la naturaleza tras el encuentro con lo divino. Su cuerpo no repite los estereotipos de la sensualidad caribeña (mulatez, frutas, entorno soleado), sino que se contextualiza en el cuerpo de una mujer intelectual que puede apreciar las maravillas culturales del viejo continente, al mismo tiempo que puede cargar en su propio cuerpo el peso de la isla, convertida ella en isla flotante, en bruja y 
sabia, en las partes de un cuerpo caribeño que no es uno sólo, sino múltiple y diverso.

El tema de la insularidad, además, aparece asociado con otro objeto fractal: la maleta, símbolo del peso de la experiencia, receptáculo de otros objetos personales que intentan resumir la experiencia cotidiana. Para cualquiera que viaja, una maleta es un resumen; para el que emigra, una vida. De este modo varias maletas se cruzan en la novela. En "El olvido insular", la evocación al poeta jamaicano Claude McKay, quien murió en New York con nostalgia de su isla, le hace recordar a su amigo el Negro, de visita también en New York, comprando cosas para todos mientras prepara su regreso a Cuba; o las maletas de Sandra, 6 "y pensaba en cuánto de arraigo había en el equipaje que cada cual llevaba consigo. Y se le antojaba la maleta -casa, sillón de madera, balsa, ataúd- un gran barco en el que podría viajar de regreso a la isla, disfrutando el paisaje del Caribe" (Mateo Palmer, 2010: 260-261).

La hermana María Estela, desde Miami, imposibilitada prácticamente de saber de Gelsomina debido a la dificultad de las comunicaciones, prepara un viaje a Cuba. Pero la maleta debe ir cargada de presentes y de extraños objetos que la madre pide. El regreso, la visita a Cuba, es una ordalía física que comienza en las tiendas más raras de Hialeah y pasa por los aeropuertos de dos países que viven de espaldas. Esa misma distancia de la hermana es lo que Gelsomina no quiere para sí. El viaje de regreso de la hermana, un poco como el de Césaire, en su famoso poemario Cahier du retour au pays natal, comienza por la mirada a vuelo de pájaro sobre la desolación del país que se ha dejado atrás. "El vuelo insular" se abre con una cita a un poema de Nicolás Guillén. Mientras el agua inunda la sala del hospital Gelsomina pide fuerzas para huir: "sé

${ }^{6}$ Mateo Palmer hace alusión a Sandra Ramos, artista cubana que a partir de los 90 comenzó a utilizar frecuentemente las maletas, como metonimia del fuerte proceso de migración ocurrido en Cuba en esta década. 
como el héroe de Derek Walcott, que se aventuró por los mares y emprendió un viaje sin fin. Vence las distancias de tu isla sumergida, abandona el mar picando a tus espaldas" (Mateo Palmer, 2010: 122). Sin embargo, una vez que imagina la distancia real de la tierra natal, lo que implica un viaje sin regreso, Gelsomina se da cuenta de que "no está preparada para esa ausencia... No partiría como Gertrudis, ni tendría que gritar adiós a las costas de su país natal cuando el ancla se alzara y crujiera la turgente vela" (125). El viaje, el vuelo de los otros, se convierte para ella en la certeza de que no puede emigrar, a pesar de las dificultades que la han llevado al extremo de la locura. Gelsomina no las menciona, pero la hermana, desde fuera, desde el contexto de Miami, puede ser más atrevida: "Ahora me cuenta nuestra madre que tú también has estado escuchando voces. Días antes del ingreso empezaste a decir que se iba a acabar el aire, que pronto iban a racionarlo por la libreta de abastecimiento, que había que empezar a ahorrar" (137). Racionar el aire, asfixia, es lo que experimentó Gelsomina, y de esa asfixia sólo puede salir por el camino de la escritura, de la ficción, y de la lectura.

Mientras la hermana prepara entonces su visita, Gelsomina planea su propio viaje de regreso, una vuelta a la realidad que coincide con el fin de la novela. Pero este final, como ya sabemos, está marcado por la entropía, la irreversibilidad y la incertidumbre: el que se va no es el mismo que regresa, y Gelsomina lo sabe, como también sabe que la vuelta al orden no es más que otro -tal vez precario- estado de equilibrio. Gelsomina bruja, Gelsomina isla, con una plegaria que no es sino un verso de Novás, "Gelsomina montó nuevamente en su balsa. Sin mirar hacia atrás, comenzó el lento regreso hacia el mundo cotidiano" (284). En este último capítulo, donde se invoca a Orula y a las diosas de las aguas, cerrando el círculo mitológico de referencias a los dioses del panteón yoruba, la Gelsomina de Mateo, como antes hizo la Gelsomina de la película 
y la del poema de Novás, termina arrodillada frente al mar, para que las diosas "con la fuerza de su amor, curen las heridas, laven las llagas y cierren los poros de la angustia" (286).

Martin Meisel, en su análisis sobre el caos en la literatura, explica a partir de la obra El Rey Lear cómo la representación de la locura en distintas obras de arte y trabajos literarios es una expresión de un fenómeno social mayor, en muchos casos, la existencia de las guerras: "Madness, the mind in chaos... is the echo of the disastrous fracturing in society, with both echoed in turn in Nature and the cosmos and made manifest in the central eruption of the storm" (2016: 480). Claro que esa "fractura de la sociedad" puede tener múltiples causas, que van desde las guerras y los efectos que producen -lo que hoy conocemos como síndrome de estrés postraumático (PTSD en inglés), hasta condiciones de depresión, ansiedad y bipolaridad más individualizadas-. En la literatura, sin embargo, se repiten aún muchos estereotipos acerca de la locura como una representación simbólica del desequilibrio personal ante situaciones sociales y familiares negativas.

En el caso de Desde los blancos manicomios, la locura de Gelsomina se puede ver como la expresión de un desorden social y un mundo fracturado, que en este caso coincide con la realidad cubana durante los años 90 y los primeros años de los 2000, años de profunda crisis económica tras la caída del campo socialista, y que fueron llamados eufemísticamente "período especial". Este contexto aparece representado desde la narración de la madre, el hijo y la hermana, quienes sitúan específicamente las situaciones e historizan el trauma de Gelsomina. Son ellos quienes comentan las dificultades de María Mercedes Pilar de la Concepción -nuestra Gelsomina cuerda-para criar sola un hijo, intentando hacer de figura materna y paterna a la vez, en un ambiente donde continúa imperando el machismo y el hombre debe defender su respeto a fuerza de golpes. Es la madre quien cuenta las travesías de una 
vida de escaseces económicas donde, en el caos de los noventa, recoger un animal de la calle era un acto de sacrificio para los seres humanos pues - literalmente- no había comida para todos. Es la hermana quien se encarga de criticar un país del que ha emigrado para poder sustentar necesidades básicas, a pesar de que se sienta frustrada, alienada y profundamente sola entre los carros y supermercados de Miami. Gelsomina no habla de esto: su refugio ante todas las carencias es su acto intelectual, su creatividad, su creencia en la vida espiritual por encima de lo material, lo que, si bien la lleva a la desazón y el manicomio, es a la vez la puerta de entrada a un mundo de creación literaria, del poder del individuo frente a una sociedad que ha sido incapaz de proveer para sus ciudadanos el cumplimiento de las necesidades más básicas.

$\mathrm{Al}$ crear un personaje/ensayista/crítico literario, que revive y transforma los tropos de la locura y la feminidad como nuevos espacios de orden, Mateo Palmer crea un modelo de creatividad y agencia intelectual únicos en las letras cubanas. A través de su discurso sobre la insularidad, las brujas, los meta-archipiélagos caribeños y el agua por todas partes, Gelsomina se rehúsa a caer en lo chato del lenguaje y de la vida cotidianos, y se embarca en un viaje donde ella resulta el timonel de su existencia, la agente intelectual de sí misma. En ese viaje, el espacio del personaje se multiplica fractalmente, no sólo debido a su condición mental, sino porque su cerebro, como el texto de la novela, ocupa un espacio literario ajeno a la realidad perentoria de la Cuba que le toca vivir, un espacio disipativo donde un nuevo orden puede surgir en medio del caos. A ese nuevo orden apela Gelsomina, quien busca, con la ayuda de las diosas, sanar sus heridas y su angustia, que es sanar también el cuerpo doliente de la isla que ella representa. Gelsomina-Isla es también, entonces, encarnación del Caribe y de Cuba. Su drama es el de todos. ¡Rema, Gelsomina! 


\section{Bibliografía}

Benítez Rojo, Antonio, 1989, La isla que se repite: el Caribe y la perspectiva posmoderna, Ed. del Norte, Hanover.

Capote Cruz, Zaida, 2013, "Los desafíos de la libertad. Narradoras cubanas de hoy", Revista Iberoamericana, vol. LXXIX, núm. 243 , abril - junio 2013, pp. 535-557.

Díaz Mantilla, Daniel, 2015, "Escribir en crisis. Margarita Mateo entre el ensayo y la ficción”, Temas, vol. 81-82, enero- junio, pp. 174-176.

Esteban, Ángel, 2006, "Raúl Hernández Novás informa sobre sí mismo: los Sonetos a Gelsomina”, Renacimiento, núm. 51/54, pp. 108-126. Disponible en: www.jstor.org/stable/40516131 (Consultado: 14/XII/2017).

Halpern, Paul, 2017, The Quantum Labyrinth: How Richard Feynman and John Wheeler Revolutionized Time and Reality, Basic Books, New York.

Hernández Novás, Raúl, 1991, Sonetos a Gelsomina, Ed. Unión, La Habana.

Lagarde y de los Ríos, Marcela, 2003, Los cautiverios de las mujeres: madresposas, monjas, putas, presas y locas, UNAM, México.

Lemaître, Monique J., 1994, "Sobre Raúl Hernández Novás, Sonetos a Gelsomina", Revista Iberoamericana, vol. 60, núm. 166, pp. 596-602.

Mandelbrot, Benoit B, 2012, The Fractalist. Memoir of a Scientific Maverick, Pantheon Books, Nueva York.

Mateo Palmer, Margarita, 2010, Desde los blancos manicomios, Atom Press, Estados Unidos. , 1995, Ella escribia poscritica, Ed. Abril, La Habana. 
Mateo Palmer, Margarita y Luis Álvarez Álvarez, 2005, El Caribe en su discurso literario, Ed. Oriente, Santiago de Cuba.

Meisel, Martin, 2016, Chaos Imagined: Literature, Art, Science, Columbia University Press, Nueva York.

Mohrhoff, Ulrich, 2014, The World According to Quantum Mechanics: Why the Laws of Physics Make Perfect Sense after All, World Scientific Publishing Co Pte Ltd, Hackensack, Nueva Jersey. Disponible en: ProQuest Ebook Central, https://ebookcentral.proquest.com/lib/miami/detail.action?docID $=840593$ (Consultado: 14/XII/2017).

Murray-Román, Jeannine, 2015, "Rereading the Diminutive: Caribbean Chaos Theory in Antonio Benítez-Rojo, Edouard Glissant and Wilson Harris", Small Axe, vol. 19, núm. 1, pp. 20-36. Disponible en: Project MUSE, muse.jhu.edu/article/577668 (Consultado: 14/XII/2017).

Pérez Hernández, Sergio, 2013, "Concierto teatral en pleno discurso ensayístico: una lectura escénica de la novela de Margarita Mateo", Tablas, vol. CII, núm. 2, pp. 37-44.

Piñera, Virgilio, "Isla", s.f., Cubaliteraria: Virgilio Piñera. Ed: Enrique Saínz. Disponible en: http://www.cubaliteraria.cu/autor/ virgilio_pinnera/index.html (Consultado: 14/XII/2017).

Prigogine, Ilya, 1993, El nacimiento del tiempo, Tusquets, Barcelona.

Timmer, Nanne, 2014, "La imaginación del cuerpo, de su entorno y de lo natural en Desde Los Blancos Manicomios, de Margarita Mateo", Cuadernos de Literatura del Caribe e Hispanoamérica, vol. 20, julio-diciembre, pp. 139-148. Disponible en: http//:investigaciones.uniatlantico.edu.co/revistas/index. php/cuadernos_literatura/article/view/139 (Consultado: 14/ XII/2017).

Ulanov, Ann Belford, 2013, Madness and Creativity. Texas A\&M University Press, College Station. Disponible en: ProQuest 
Valenciana, ISSN impresa: 2007-2538, ISSN electrónica: 2448-7295, núm. 22, julio-diciembre de 2018, pp. 193-215.

Ebook Central, https://ebookcentral.proquest.com/lib/miami/ detail.action?docID=1180040 (Consultado: 14/XII/2017). 